\title{
Immigration of prokaryotes to local environments enhances remineralization efficiency of sinking particles: a metacommunity model
}

\author{
Takeshi Miki ${ }^{1,4}$, Taichi Yokokawa ${ }^{2}$, Toshi Nagata ${ }^{1,5}$, Norio Yamamura $^{3}$ \\ ${ }^{1}$ Center for Ecological Research, Kyoto University, Hirano 2-509-3, Otsu, Shiga 5202113, Japan \\ ${ }^{2}$ Department of Biological Oceanography, Royal Netherlands Institute for Sea Research PO Box 59, 1790 AB Den Burg, \\ The Netherlands \\ ${ }^{3}$ Research Institute for Humanity and Nature, 457-4 Motoyama, Kamigamo, Kita-ku, Kyoto 603-8047, Japan \\ ${ }^{4}$ Present address: Institute of Oceanography, National Taiwan University, No. 1, Sec. 4, Roosevelt Rd., Taipei 10617, Taiwan \\ ${ }^{5}$ Present address: Marine Biogeochemistry Group, Department of Chemical Oceanography, Ocean Research Institute, \\ The University of Tokyo, 1-15-1 Minami-dai, Nakano, Tokyo 164-8639, Japan
}

\begin{abstract}
Processing of organic matter by heterotrophic prokaryotes regulates carbon sequestration in the ocean, and thus influences the global climate. Recent studies have begun to elucidate the remarkable diversity of oceanic prokaryotes with estimates of $>1000$ species or phylotypes in a single local habitat and up to 2 million in the global ocean. However, how this prokaryotic diversity and spatial heterogeneity in their compositions contribute to regional variations in major biogeochemical fluxes driven by heterotrophic prokaryotes is still unclear. A new theoretical model integrating the metacommunity concept with oceanic biogeochemistry demonstrates that increased production of particulate organic carbon (POC) leads to increased efficiency of remineralization of POC in the surface ocean, affecting the carbon export to deep waters. This is attributed to flexible shifts in the local prokaryotic community composition in response to changes in primary production, which is facilitated by the high degree of diversity in the metacommunity and moderate immigration rates of prokaryotes into the local community. By linking the spatial heterogeneity of microbial communities to their transient dynamics, a metacommunity concept will improve our understanding of the regional variability of biogeochemical processes in the oceans.
\end{abstract}

KEY WORDS: Theoretical model - Biological pump · Carbon cycle $\cdot$ Biodiversity $\cdot$ Bacteria $\cdot$ Metacommunity

Resale or republication not permitted without written consent of the publisher

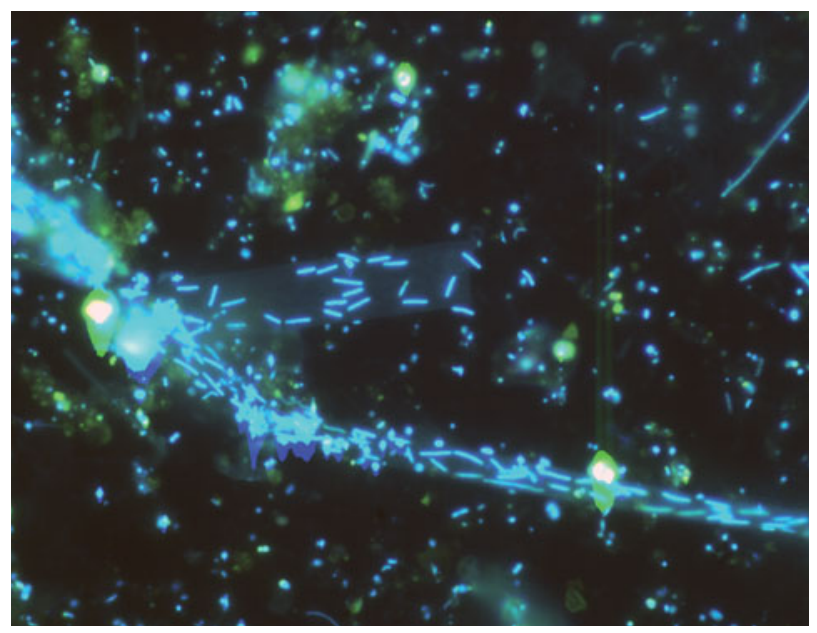

Prokaryotes play the principal role in remineralization of particulate organic carbon in seawater.

Photo: Yoko Nishimura

\section{INTRODUCTION}

Prokaryotic heterotrophs represent an integral part of the oceanic biological pump that exports organic carbon from the sunlit layer to the ocean interior (Ducklow et al. 2001). This process contributes to the sequestration of large amounts of carbon for up to $1000 \mathrm{yr}$ in deep waters and influences the global car- 
bon cycle and climate (Sarmiento \& Gruber 2006). Heterotrophic prokaryotes control the magnitude of vertical organic carbon fluxes through 2 fundamental processes: dissolution of sinking particulate organic carbon (POC) and mineralization of particulate and dissolved organic carbon (DOC) (Cho \& Azam 1988, Smith et al. 1992, Nagata et al. 2000). Previous studies examining the roles of microbial systems in carbon cycling treated heterotrophic prokaryotes as a single functional group, even though oceanic prokaryotic communities consist of multiple species or ecotypes with distinctive physiological traits (Cottrell \& Kirchman 2000, Elifantz et al. 2005, Bouman et al. 2006). Phytoplankton community structure and heterotrophic activities of zooplankton and prokaryotes have been considered to be important determinants of the fraction of export production over primary production (export ratio) (Laws et al. 2000, Rivkin \& Legendre 2001, Dunne et al. 2005), which are highly variable at regional scales (Antia et al. 2001, Sarmiento \& Gruber 2006). However, how community structure of prokaryotes may affect the regional variability in the functioning of the biological pump has yet to be explored fully.

Recent studies have begun to elucidate the remarkable diversity of oceanic prokaryotes (Giovannoni \& Stingl 2005), with estimates of $>1000$ phylotypes in a single habitat (Acinas et al. 2004, Venter et al. 2004) and up to 2 million in the global ocean (Curtis et al. 2002). Oceanic prokaryotic communities exhibit large variations in composition at various scales in both time (from days to seasons) (Murray et al. 1998, Riemann et al. 2000) and space (from 10 to $1000 \mathrm{~km}$ ) (Kirchman et al. 2005, Pommier et al. 2005, Hewson et al. 2006). However, other studies have shown that a certain phylogenetic group is cosmopolitan (e.g. Pelagibacter ubique [SAR11]: Morris et al. 2002, Pommier et al. 2005), suggesting that spatial variability in prokaryote community compositions in general is less pronounced (Green \& Bohannan 2006). It is unclear how this prokaryotic diversity and their spatio-temporal distribution patterns affect major biogeochemical fluxes driven by heterotrophic prokaryotes in the oceans (DeLong \& Karl 2005).

High dispersal ability of prokaryotes has led to a proposition that 'everything is everywhere, but the environment selects' (reviewed by Fenchel \& Finlay 2004, de Wit \& Bouvier 2006). This concept hypothesizes that spatial variations in dominant members of prokaryotic communities are attributed to environmental heterogeneity and its selection, assuming that local community members including rare groups vary little globally. It has been speculated that rapid temporal shifts of dominant members in response to local environmental changes are achieved by rapid growth of rare groups (a 'seed bank') within a local community
(Pernthaler et al. 1998, Riemann \& Winding 2001). An alternative view is that high dispersal ability of prokaryotes allows immigration of various types of prokaryotes into a local community, contributing to the maintenance of rare groups under suboptimal conditions. This mechanism can facilitate an adaptive shift in community composition in response to changes in local environments. The latter view ('everything goes everywhere, the environment selects') represents a kind of 'metacommunity' concept, which has been developed in ecology during the last decade (Norberg et al. 2001, Loreau et al. 2003, Leibold et al. 2004). The key aspect of the metacommunity concept is that spatially connected local communities with dispersal of cells are capable of tracking the spatio-temporal variations in the environment by flexible shifts in community composition (Leibold \& Norberg 2004, Kitayama 2005).

In the present paper, we hypothesize that both rapid growth of rare groups within a community and immigration of various groups into a community facilitate adaptive shifts of local prokaryotic communities to environmental changes, which affect the major biogeochemical fluxes driven by heterotrophic prokaryotes in the oceans. We adopt a simple conceptual model (Thingstad \& Lignell 1997). Our aim is to illustrate this type of metacommunity thinking, which can potentially link prokaryotic diversity, its spatio-temporal distribution, and biogeochemical cycling. We do not intend to provide a comprehensive model of oceanic carbon cycling, which is driven by various members of food webs (e.g. Sarmiento et al. 1998, Lancelot et al. 2000). Rather, we focus on a single compartment of heterotrophic prokaryotes and try to extract essential features of complex reality in order to help improve regional models of oceanic ecosystems. By extending recent metacommunity concepts (Leibold \& Norberg 2004, Kitayama 2005) and models (Norberg et al. 2001, Loreau et al. 2003) to oceanographic settings, we show that regional diversity of prokaryotes and dispersal of prokaryotic cells among local communities determine the flexibility of local prokaryotic communities to environmental changes and act as a major determinant of carbon sequestration in the ocean.

\section{METHODS}

Consider a local community of prokaryotes in a homogenous water column of the euphotic zone (upper $200 \mathrm{~m}$ ), where $N$ ecotypes of prokaryotes interact with each other competing for 2 distinctive pools of organic carbon, POC and DOC. Prokaryotes exist either as individual cells suspended in bulk water (free living) or as cells attached to POC (attached); the latter are 
referred to as aggregates when considering POCprokaryote complexes (Miki \& Yamamura 2005). Each ecotype is suggested to have different strategies for utilizing POC and DOC (Kirchman 2002), which can be represented by the following 4 ecotype-specific traits. Ecotype-specific traits for Ecotype $\mathrm{j}$ are the hydrolysis rate of POC $\left(h_{\mathrm{j}}\right)$, the fraction of organic carbon taken up by an attached cell relative to the total hydrolyzed POC $\left(u_{j}\right)$, attachment rate of free-living cells to POC $\left(a_{\mathrm{j}}\right)$ and detachment rate of particle-attached cells to become free-living organisms $\left(d_{\mathrm{j}}\right)$ (Fig. 1). Ecotypes with low $h_{\mathrm{j}}$ remain on the same particle for long periods, and the growth of ecotypes with low $u_{\mathrm{j}}$ is highly uncoupled with hydrolysis. Ecotypes with high $a_{\mathrm{j}}$ and those with high $d_{\mathrm{j}}$ show preferences for POC and DOC, respectively. Our model parameterizes the major processes involved in organic matter transformations in the upper oceans (Ducklow et al. 2001): (1) DOC and POC supply, as primary production; (2) loss by grazing and sinking; (3) hydrolysis of aggregates, consumption of hydrolyzed carbon by particle-attached prokaryotes and DOC release; and (4) competition among all ecotypes (for DOC resulting in free-living prokaryotic consumption of DOC, and for POC resulting in aggregate formation) (Fig. 1). Parameters in these processes are based on empirical data: the growth efficiency of prokaryotes (del Giorgio \& Cole 2000), mortality of

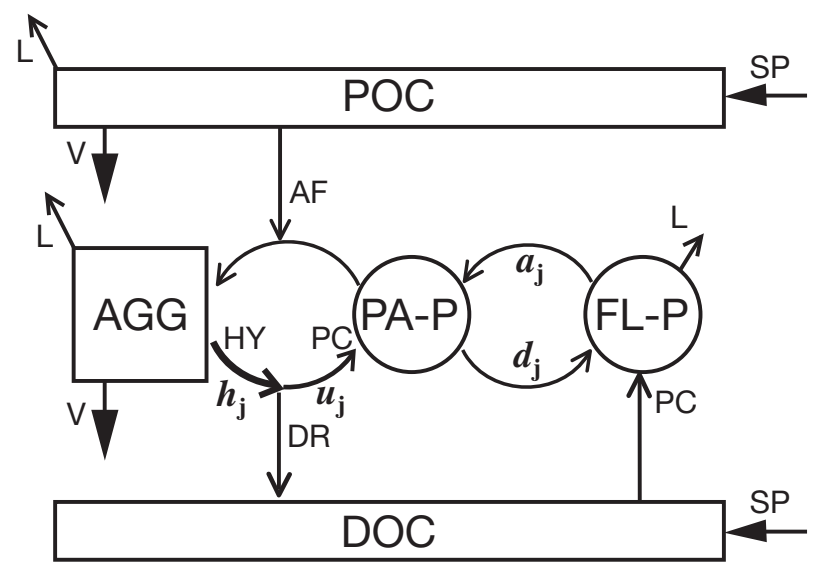

Fig. 1. Model flow diagram. AGG: aggregates consisting of particulate organic carbon (POC) and particle-associated prokaryotic cells of Ecotype j (PA-P); FL-P: free-living prokaryotic cells of Ecotype $j_{i}$ L: loss by grazing; V: vertical sinking of fresh particles (POC) and aggregates; AF: aggregate formation (colonization of fresh POC by cells); HY: hydrolysis of POC; PC: prokaryotic consumption of hydrolyzed POC or dissolved organic carbon (DOC), which results in prokaryotic production and remineralization to $\mathrm{CO}_{2}$ DR: DOC release from aggregates; SP: supply of organic carbon. Ecotypespecific traits of Ecotype $\mathrm{j}$ are as follows: hydrolysis rate of aggregates $\left(h_{\mathrm{j}}\right)$, uptake ratio of hydrolyzed carbon $\left(u_{\mathrm{j}}\right)$, the rate at which free-living cells change state into cells using POC $\left(a_{j}\right)$ (attachment rate) and the rate at which newly produced cells on aggregates change into cells using DOC (detachment rate) $\left(d_{\mathrm{j}}\right)$ prokaryotes (Strom 2000, Grossart et al. 2003), maximum uptake ratio of hydrolyzed carbon (Smith et al. 1992), and the supply rate of organic carbon (on the same order as primary production) (Williams 2000) (see Appendix 2 for details).

Note that prokaryotic consumption of organic carbon results in prokaryotic production and remineralization to $\mathrm{CO}_{2}$. In addition to these local processes, consider a regional process: immigration of free-living cells of each ecotype from a metacommunity in which $N$ $(=1000)$ ecotypes with differing trait values coexist (i.e. ecotype-specific parameters are assigned randomly to each ecotype), at a rate of $I_{\mathrm{m}} / N$ per ecotype per unit volume, where $I_{\mathrm{m}}$ is the total abundance of immigrants, i.e. the immigration rate. Both local processes and this regional process determine the abundance of freeliving cells at the next time step (the model formulation is described in further detail in Appendices 1, 2, \& 3).

In our model, the abundance of prokaryotic cells and the concentration of carbon resources are changed in a step-by-step manner (i.e. discrete time model). We assumed the day as the time step, and therefore simulated the changes in the abundance of each ecotype and the carbon fluxes on a per day basis. We assumed the changes in carbon resource supply at $t=1000$ (days): $\left(s_{\mathrm{DOC}}, s_{\mathrm{POC}}\right)=(10.0,1.0)$ if $0 \leq t<1000,\left(s_{\mathrm{DOC}}\right.$, $\left.S_{\mathrm{POC}}\right)=(10.0,10.0)$ if $\left.1000 \leq t<1000+T_{\text {bloom }}\right)$, where $S_{\mathrm{DOC}}$ and $S_{\mathrm{POC}}$ are supply rate of DOC and of POC ( $\mu \mathrm{g} \mathrm{C}$ $\left.\mathrm{l}^{-1} \mathrm{~d}^{-1}\right)$, respectively, and $T_{\text {bloom }}$ is the period of the phytoplankton bloom in which POC supply rate is high. A period of $1000 \mathrm{~d}$ is sufficient for the system to reach equilibrium with low supply rates of DOC and POC. To examine the effects of immigration (Figs. 2, 3 \& 4), we first prepared 1000 metacommunities, each of which consisted of 1000 ecotypes, the ecotype-specific parameters of which $\left(h_{j}, u_{j}, a_{j}, d_{j}\right)$ were selected randomly from uniform distributions. For each metacommunity, we examined the response of the local community connected with the metacommunity, depending on the immigration rate.

In order to examine if the predictions derived from the above model are robust or simply reflect the assumptions embedded in the model, we constructed alternative models using different assumptions regarding (1) mortality, (2) immigration processes, and (3) the use of DOC and POC. First, we considered 3 types of different modes of mortality of prokaryotes: density-independent mortality; ecotype-specific, density-dependent mortality; and non-selective, densitydependent mortality. Ecotype-specific, density-dependent mortality simulates the existence of ecotypespecific natural enemies such as viruses (assuming that the abundance of the natural enemy is proportional to the abundance of each prey [ecotype]), whereas the non-selective, density-dependent mortality simulates 

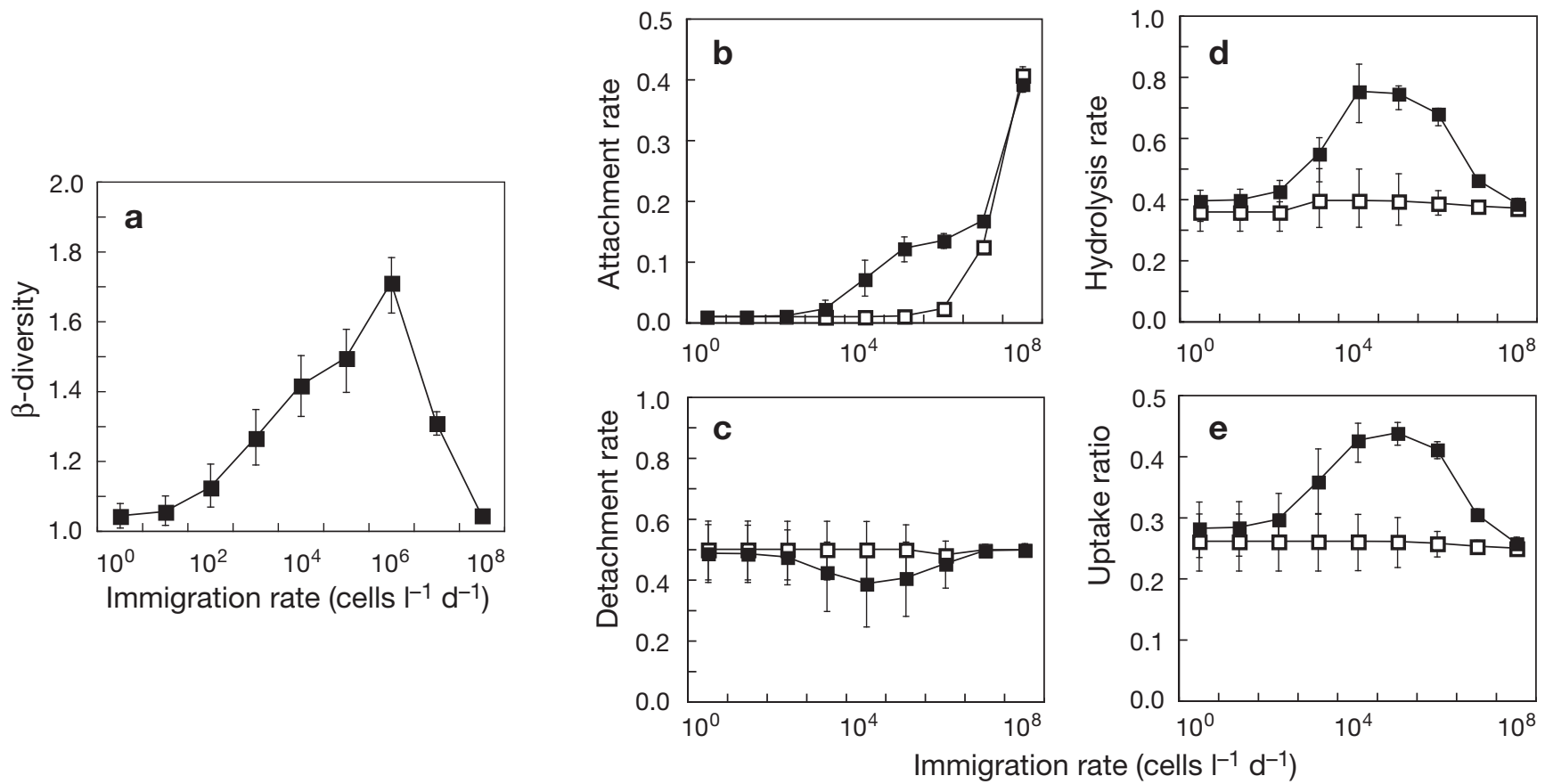

Fig. 2. Effects of the immigration rate on $\beta$-diversity and shifts in community-averaged traits. (a) $\beta$-diversity is defined as $\gamma$-diversity/ $\alpha$-diversity $=2 \times$ (total number of detectable ecotypes before or after changes in POC supply) / (number of detectable ecotypes before the changes + number of detectable ecotypes after the change). $\beta$-diversity is 1.0 when there is no replacement of community members, whereas it becomes 2.0 when complete replacement occurs. We regarded ecotypes with relative abundance of $>0.1 \%$ of total prokaryotic cells as detectable ecotypes. (b to e) Community-averaged traits are calculated as the sum of relative density-weighted traits of each ecotype. For (a-e), each square represents the average value from 1000 simulations using different metacommunities, and each error bar represents the middle $95 \%$ ranges from 1000 simulations. For (b-e), the open and closed squares represent the community-averaged traits before and after the change in POC supply, respectively. y-axis parameters are dimensionless
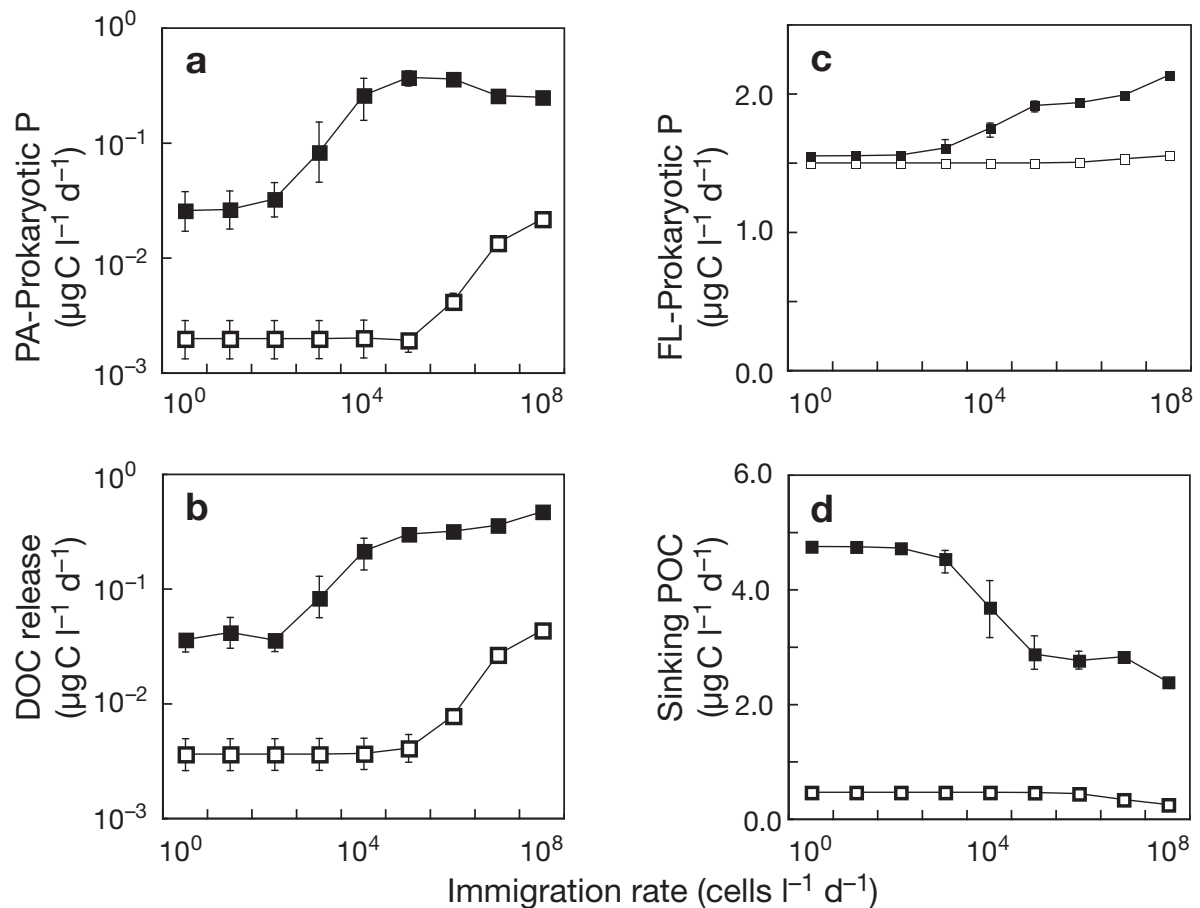

Fig. 3. Effects of the immigration rate on carbon fluxes. (a) Prokaryotic production by particle-attached cells (PA-P). (b) Dissolved organic carbon (DOC) release from aggregates. (c) Prokaryotic production by free-living cells (FL-P). (d) Sinking flux of particulate organic carbon (POC). For $(\mathrm{a}-\mathrm{d})$, each square represents the average value from 1000 simulations using different metacommunities, and each error bar represents the middle $95 \%$ range from 1000 simulations. The open and closed squares represent the carbon fluxes before and after the change in POC supply, respectively 

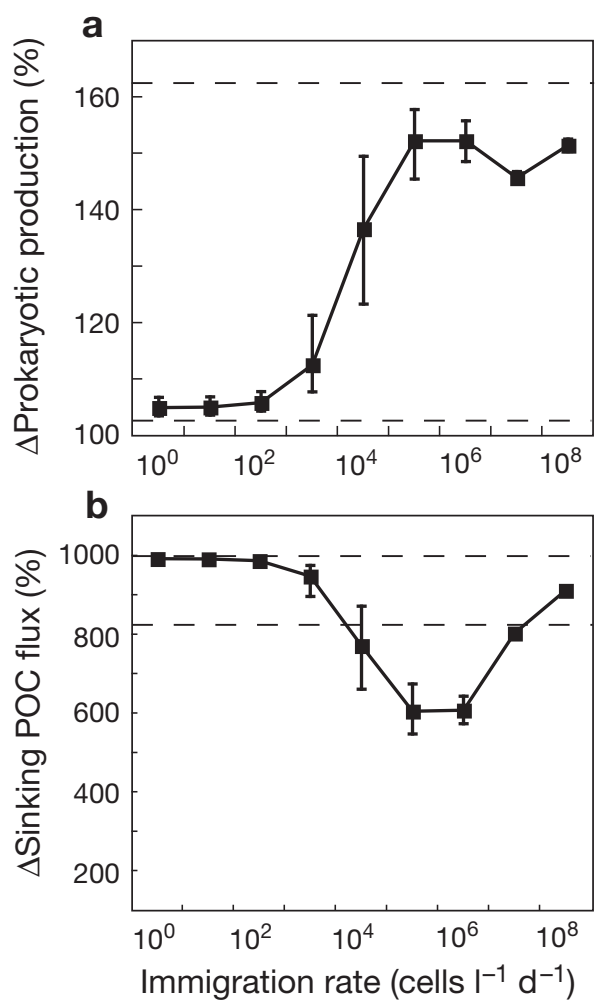

Fig. 4. Relative changes in major carbon fluxes in response to increases in POC supply. (a) Difference in total prokaryotic production (particle-attached plus free-living fraction of prokaryotic production) before and after the increase in POC supply. (b) Difference in sinking flux of POC before and after the increase in POC supply. These differences were calculated as the values after the increase in POC supply divided by the values before the increase. For $(a, b)$, each square represents the average value from 1000 simulations, and each error bar represents the middle 95\% range from 1000 simulations. The range between upper and lower dashed lines represents the middle $95 \%$ of responses of prokaryotic monoculture community from 1000 simulations

the existence of generalist protozoan predators (assuming that the abundance of the natural enemy is proportional to the total abundance of all prey [ecotypes]). Second, we examined the behavior of model properties under the assumption of several alternative regional processes. We considered both the deterministic and the stochastic immigration processes. We also considered the cases with 'balanced' emigration, assuming that the total number of prokaryotes in inflow is the same as the number of prokaryotes in outflow, and the cases without emigration. In addition, we considered the cases with a common immigration rate for all ecotypes and the cases with ecotype-specific immigration rates. Third, we considered the trade-off between the efficiency of utilizing POC and DOC for each ecotype, assuming that ecotypes with higher hydrolysis rates have a low ability to consume DOC. The following results are based on simple default assumptions: (1) density-independent mortality rate of prokaryotes, (2) a deterministic immigration and balanced-emigration rate, which is common for all ecotypes, and (3) no trade-off between the abilities of utilizing POC and DOC.

We also examined the case in which the immigration rate is different before and after the bloom, in order to separate the effects of immigration before the bloom and those after the bloom on the response of the system to the environmental changes. We set 4 scenarios: the case with a low immigration rate $\left(10^{0}\right.$ cells $\left.\mathrm{l}^{-1} \mathrm{~d}^{-1}\right)$ both before and after the bloom ('Low-Low'), the case with a low immigration rate $\left(10^{0}\right.$ cells $\left.\mathrm{l}^{-1} \mathrm{~d}^{-1}\right)$ before the bloom and a high rate $\left(10^{6}\right.$ cells $\left.\mathrm{l}^{-1} \mathrm{~d}^{-1}\right)$ after the bloom ('Low-High'), the case with a high immigration rate before the bloom and a low rate after the bloom ('High-Low'), and the case with a high immigration rate both before and after the bloom ('High-High').

\section{RESULTS}

We investigated the responses of the local prokaryotic community to increases in POC supply, which are representative of typical changes in primary production during phytoplankton blooms. We compared the community composition before the increase in POC supply, when the system had almost reached equilibrium in environments with low POC supply $(1.0 \mu \mathrm{g}$ $\left.\mathrm{C}^{-1} \mathrm{~d}^{-1}\right)$, and $100 \mathrm{~d}$ after the increase $\left(10.0 \mu \mathrm{g} \mathrm{C}^{-1}\right.$ $\left.\mathrm{d}^{-1}\right)$, with constant supply rate of DOC $\left(10.0 \mu \mathrm{g} \mathrm{C}^{-1}\right.$ $\mathrm{d}^{-1}$ ). We replicated 1000 simulations for each immigration rate using different metacommunities. The model predicts that shifts in community composition, calculated by $\beta$-diversity representing the differences in community composition before and after the increase in POC supply, are greatest at intermediate levels of immigration (Fig. 2a). This pattern implies that the sorting process (Leibold \& Norberg 2004), which selects locally adapted ecotypes, functions effectively with moderate connections among local communities, being consistent with previous predictions (Loreau et al. 2003, Leibold \& Norberg 2004). This shift in community composition does not occur completely when the immigration rate is so low that adaptive ecotypes cannot replace the community during the bloom $(100 \mathrm{~d})$, due to their low density before the increase in POC supply. If the immigration rate is very high, the local community composition is largely determined by the composition of the metacommunity independent of the POC supply rate, and then no shift in community composition occurs. The shifts in community composition are accompanied by shifts in community-averaged traits, with intermediate levels of immigration (Fig. $2 b$ to e). Community-averaged values of attachment rate 
to POC (Fig. 2b), hydrolysis rate (Fig. 2d) and uptake ratio (Fig. 2e) become substantially higher than the values before the increase in POC supply, whereas community-averaged detachment rate (Fig. 2c) does not show clear changes independent of the immigration rate. These observations suggest that the increase in POC supply results in dominance of prokaryotes with higher attachment rate, higher hydrolysis rate and higher uptake ratio of hydrolyzed carbon.

These shifts, in turn, determine the responses of prokaryote-mediated carbon fluxes (Fig. 3); the degrees of increase in carbon fluxes are largely influenced by the immigration rate. In comparison to cases with very low immigration rates, the degree of increase in the particle-attached fraction of prokaryotic production is much higher, with intermediate immigration rate (Fig. 3a). This leads to a higher DOC release rate (Fig. 3b) that, in turn, enhances the free-living fraction of prokaryotic production (Fig. 3c), suppressing the increase in sinking flux of POC (Fig. 3d). These trends can be seen clearly when we calculate the differences before and after the increase in POC supply (Fig. 4). The degree of increase in total prokaryotic production is highest (Fig. 4a), and thus the degree of increase in sinking flux of carbon is most suppressed (Fig. 4b), with intermediate levels of immigration (10-fold increase in POC supply results in only 6-fold increase in sinking flux). That is, the adaptive shifts of the prokaryotic community lead to more efficient consumption of POC in the surface ocean, and a decrease in efficiency of sinking flux of POC to the deep ocean. It follows that the increase in the export ratio is suppressed, which generally increases with the primary production (Laws et al. 2000, Dunne et al. 2005). In our simulations, the export ratio before the bloom is $4.5 \%$ and becomes $16 \%$ after the bloom, with intermediate levels of immigration, whereas it becomes $25 \%$ with very low levels of immigration. Note that these values fall into the range of previous observations (Laws et al. 2000, Dunne et al. 2005, Sarmiento \& Gruber 2006). Extensive numerical simulations using various assumptions regarding mortality, immigration processes and the use of DOC and POC revealed that our predictions do not vary depending on assumptions. Generally, the degree of increase in sinking flux of carbon is most suppressed with intermediate levels of immigration, although the degree of suppression depends on the assumptions (from 6.0- to 8.8-fold increase in sinking flux, in response to a 10 -fold increase in POC supply) (see Appendix 4 for details).

We also compared the adaptive shifts of the prokaryotic community with the responses of monoculture prokaryotic communities consisting of 1 ecotype chosen at random to evaluate the effects of prokaryotic diversity per se (Fig. 4). The region between the upper and lower dashed lines in Fig. 4 represents the middle $95 \%$ of responses from 1000 monoculture communities. These results clearly show that the increase in sinking flux of POC induced by increased POC supply is more strongly suppressed in communities with multiple ecotypes than in monoculture communities, whereas there is no clear difference in prokaryotic production between them. These observations clearly show that diversity in the metacommunity is crucial for the adaptive shift in prokaryote-mediated processes.

In addition, we examined the time evolution of the shifts in community composition and processes (Fig. 5a to c). Intermediate immigration causes shifts in community composition shortly after the change in POC supply (<100 d), whereas, with low immigration rate, the shifts in community composition take place long after the change in POC supply (>100 d). These results indicate that the lower the immigration rate, the longer the period for a system to achieve adaptive shifts (Fig. 5a), to increase prokaryotic production (Fig. 5b) and to suppress the vertical sinking of POC (Fig. 5c). Previous studies have also pointed out that immigration rate determines the rate of adaptive shifts in complex adaptive systems (Levin 1998, Norberg et al. 2001, Leibold \& Norberg 2004). Additional numerical calculations show that growth-related parameters (Appendix 2), such as the maximum uptake rate of hydrolyzed POC by particle-attached cells $\left(u_{\mathrm{MAX}}\right)$, also regulate the degree of adaptive shifts (Fig. $5 d$ to f); higher $u_{\text {MAX }}$ presumably indicates higher quality of POC. We found that if $u_{\text {MAX }}$ of particle-attached cells is high, adaptive shifts in composition (Fig. 5d) and in biogeochemical processes (Fig. 5e, f) are achieved even with low immigration rates.

Results in Fig. 5 demonstrate that both rapid growth of rare groups within a community and immigration of various groups into a community facilitate adaptive shifts of local prokaryotic communities in response to environmental changes. Additional analyses of the time evolution of the system reveal the relationships between these 2 processes. We tracked the changes in abundance of 1 specific ecotype with higher preference to POC, which can be dominant after the bloom (Fig. 6a), and the temporal shifts in the sinking flux of POC (Fig. 6b), showing that both immigration processes before the bloom and after the bloom contribute to adaptive shifts in the system. First, immigration before the bloom contributes to the persistence of the populations of rare groups that are inferior competitors before the bloom but superior after the bloom. It follows that immigration before the bloom indirectly facilitates the growth of these populations after the bloom (Fig. 6a: High-Low scenario where the immigration rate before the bloom is high but becomes low after the 

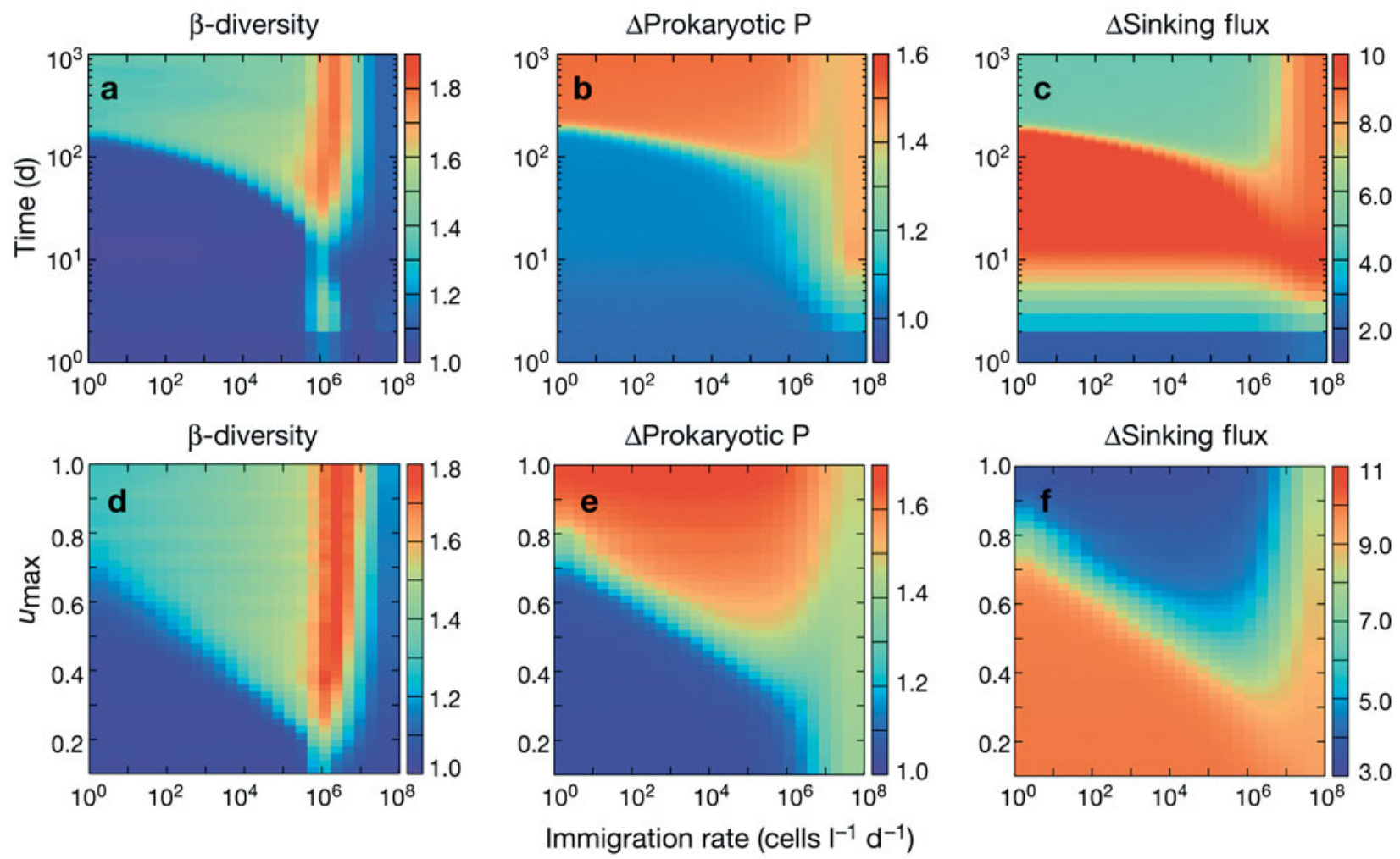

Fig. 5. Dependence of the adaptive shifts of the prokaryotic community on time and the growth parameter ( $\left.u_{\mathrm{MAX}}\right)$. (a,d) $\beta$-diversity, depending on time and $u_{\mathrm{MAX}}$, respectively. $(\mathrm{b}, \mathrm{e})$ Differences in total prokaryotic production before and after the increase in POC supply, depending on time and $u_{\mathrm{MAX}}$, respectively. $(\mathrm{c}, \mathrm{f})$ Differences in sinking flux of POC before and after the increase in POC supply, depending on time and $u_{\mathrm{MAX}}$, respectively. For $(\mathrm{a}-\mathrm{C})$, all values are from simulations using the same metacommunity (not averaged values). For $(\mathrm{d}-\mathrm{f})$, all values are averages from 10 simulations using different metacommunities $(100 \mathrm{~d}$ after the increase in POC supply). $u_{\mathrm{MAX}}$ is the maximum uptake ratio of hydrolyzed POC and higher $u_{\mathrm{MAX}}$ can be interpreted as higher quality of $\mathrm{POC}$, which results in higher growth rate of prokaryotes. Patterns qualitatively similar to the results for $u_{\mathrm{MAX}}$ were obtained for the other growth-related parameter $\left(k_{\mathrm{A}}\right.$, encounter efficiency between POC and cells; not shown); for detail see Appendices 1 \& 2

bloom), leading to the rapid shifts in community composition after the bloom and the rapid suppression of the sinking flux of carbon (Fig. 6b). Second, immigration after the bloom directly contributes to the increase in the abundance of such competitively superior but rare groups, resulting in the rapid suppression of the sinking flux of carbon, even if the immigration before the bloom is low (Fig. 6a,b: Low-High scenario where immigration rate before the bloom is low but becomes high after the bloom). Therefore, either high immigration before the bloom or after the bloom is necessary for adaptive shifts in the system (High-Low, Low-High, or High-High scenarios).

\section{DISCUSSION}

Our mechanistic model, which combines prokaryotic diversity with major processes involved in interactions between organic carbon and heterotrophic prokaryotes, has led to 2 conceptual advances in how to link prokaryotic diversity with biogeochemical cycling. First of all, it reveals distinct behaviors of prokaryotic assemblage with diverse phenotypes from those without phenotypic diversity. Prokaryotic diversity allows the local community to flexibly respond to environmental changes and affects the major carbon fluxes in the ocean (Figs. 3 \& 4). The mechanisms underlying this regulation involve flexible shifts of physiological traits at community level through shifts in community composition (Fig. 2). Second, in addition to diversity per se, application of a metacommunity model clearly demonstrates that the spatial heterogeneity in community compositions and the transport of cells can be key factors for flexible responses. They potentially contribute to the flexibility of the local community and positively affect the rate of flexible shifts in response to environmental changes (Figs. 5 \& 6).

Applicability of the metacommunity concept into oceanic prokaryotes is supported by a few lines of evidence. On the one hand, the marked variability in prokaryotic community compositions, which has been 

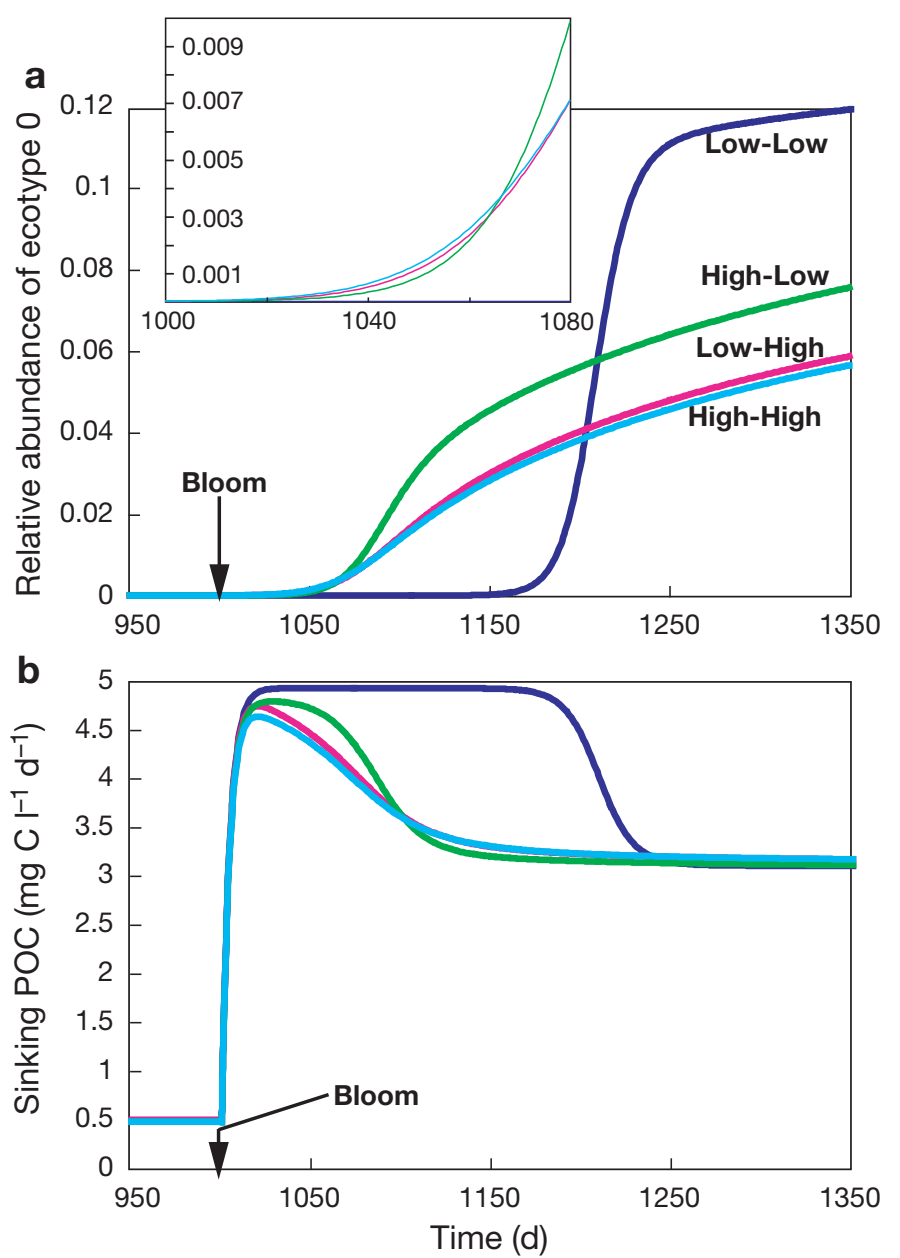

Fig. 6. Effects of the immigration before and after the bloom on the temporal changes in the abundance of 1 specific ecotype and in the sinking flux of POC. (a) Temporal changes in the relative abundance of 1 specific ecotype with higher preference to POC $(h=0.9, d=0.1, a=0.9, u=0.5)$, which is calculated by the abundance of free-living cells of this ecotype per total abundance of free-living cells. Physiological traits $(h, d$, $a, u$ ) of another 999 ecotypes are randomly chosen. (b) Temporal changes in the sinking flux of POC after the bloom. At time $t=1000$ the bloom initiates $\left(s_{\mathrm{p}}=1.0 \mu \mathrm{g} \mathrm{Cl}^{-1} \mathrm{~d}^{-1}\right.$ if $t<1000$ and $10 \mu \mathrm{g} \mathrm{C}^{-1} \mathrm{~d}^{-1}$ if $t \geq 1000$ ). Setting for 4 scenarios is follows. Low-Low: $I_{\mathrm{m}}=10^{0}$ cells $\mathrm{l}^{-1} \mathrm{~d}^{-1}$ for all $t$, Low-High: $I_{\mathrm{m}}=$ $10^{0}$ cells $\mathrm{l}^{-1} \mathrm{~d}^{-1}$ if $t<1000$ and $10^{6}$ cells $l^{-1} \mathrm{~d}^{-1}$ if $t \geq 1000$, High-Low: $I_{\mathrm{m}}=10^{6}$ cells $\mathrm{l}^{-1} \mathrm{~d}^{-1}$ if $t<1000$ and $10^{0}$ cells $\mathrm{l}^{-1}$ $\mathrm{d}^{-1}$ if $t \geq 1000$, and High-High: $I_{\mathrm{m}}=10^{6}$ cells $\mathrm{l}^{-1} \mathrm{~d}^{-1}$ for all $t$

observed in its vertical (Field et al. 1997, DeLong et al. 2006) and horizontal extents (Kirchman et al. 2005, Pommier et al. 2005, Hewson et al. 2006), clearly supports the view of a metacommunity as the assemblage of local communities with different compositions. On the other hand, microbial ecologists only have limited knowledge about how local communities are interconnected by the transport of prokaryotic cells. The transport of cells is most likely mediated by diffusion and advection (e.g. horizontal movement of water masses, upwelling, and vertical mixing), although aeolian and biotic transport may also contribute to the delivery. We would expect that the transport regime is highly variable in estuarine and coastal systems where diverse microbial habitats are connected in a complex fashion because of variable flows of water masses. In such habitats, it is likely that the exchange rate of water is too high to retain the spatial heterogeneity of bacterial community compositions and to adaptively respond to environmental changes. In the St. Lawrence estuary, it has been shown that the rate of changes in bacterial abundance due to horizontal advection and diffusion reflects approximately the same rate of changes due to local growth and grazing loss (Painchaud et al. 1996). This situation would correspond to the case with a very high immigration rate in our model, where the bacterial community is predicted not to respond adaptively. On the contrary, in the Parker River estuary, it has been shown that the distinct community composition is maintained when the average time scale of bacterial growth is shorter than the time scale of water exchange; otherwise, it is just a mixing of freshwater and marine communities (Crump et al. 2004). In open oceans and deep waters, mesoscale eddies might be a mechanism that regulates the exchange of prokaryotic members among local communities. To our knowledge, Spall \& Richards (2000) provided a unique study focused on the effects of mesoscale vertical and horizontal eddies on the distribution of bacteria by a realistic physical/ecosystem numerical model. Although there are many studies on patchiness of phytoplankton and bacterial abundance on the scale of $100 \mathrm{~km}$ (Robarts et al. 1996, Nagata et al. 2000, Martin 2003), only a few studies have demonstrated the mesoscale spatial heterogeneity in bacterial community composition (the northern North Sea; Zubkov et al. 2002). These spatial gradients at this spatial scale are necessary for effective advection and diffusion among local prokaryotic communities by mesoscale eddies. The predicted importance of transport of cells strongly suggests the necessity to evaluate the relative contribution of immigration and emigration to temporal dynamics in prokaryotes compared to local growth and grazing loss in the open oceans. At the same time, it should also be noted that horizontal and vertical movement of water inevitably transports, not only microbes, but also dissolved and particulate materials including DOC and $\mathrm{POC}$, i.e. major components of the carbon cycle and other biogeochemical cycles. If the dominant processes of transport of prokaryotic cells are mediated by water movement, evaluation of the net effect of transport of DOC, POC, and prokaryotes will be an important step for future studies.

Extensive numerical simulations revealed that the positive effect of immigration processes on adaptive 
responses of the system and the reduced efficiency of the sinking flux of POC are robust predictions, which do not depend on assumptions (Appendix 4). First, the ecotype-specific, density-dependent mortality contributes to adaptive shifts in the system at very low levels of immigration. This is because higher diversity is maintained under ecotype-specific, density-dependent mortality than under density-independent or nonselective, density-dependent mortality (Thingstad \& Lignell 1997). However, even under the condition in which ecotype-specific mortality prevails, the immigration processes have a significant effect on adaptive responses; a higher immigration rate leads to the stronger suppression of the increase in sinking flux of POC. Second, details in immigration processes do not affect the responses of the system. Therefore, we can argue that the average levels of immigration are the important determinant of adaptive responses of the system, although the details in immigration processes are still unclear in natural systems. Third, the occurrence of adaptive shifts does not depend on the presence or absence of the trade-off between the efficiency of utilizing POC and DOC at the individual cell level. This is because the default assumption that free-living (or particle-attached) cells utilize only DOC (or POC) acts as a simple trade-off between the efficiency of utilizing POC and DOC at the population level. This trade-off at the population level is a sufficient constraint, which leads to the dependence of dominant ecotypes on the relative availability of POC and DOC. Therefore, despite the simplicity and uncertainty of our model, the robustness of the predictions strongly suggests the potential importance of prokaryotic immigration in carbon export processes in natural complex ecosystems.

It should also be noted that the applicability of our model and importance of prokaryotic immigration largely depend on spatio-temporal scales of ecosystem dynamics. At the global scale, carbon export under long-term equilibrium is not strongly determined by food web structures, but by nutrient import from the land, atmosphere and deep ocean (Dugdale \& Goering 1967, Eppley \& Peterson 1979). At regional scales, however, both import from the deep ocean and export from the sunlit layer under a quasi-equilibrium state at a 10 to 100 yr scale are influenced by the food web structure in the sunlit layer, for example, by phytoplankton community composition (Laws et al. 2000, Dunne et al. 2005, Sarmiento \& Gruber 2006). Our metacommunity model is applicable to ecosystem dynamics at this spatio-temporal scale, and will help to understand the regional variability in vertical flux of carbon and its temporal changes at short time scales. Although we fixed primary production and did not consider dynamics of limiting nutrients in this model, the impact of prokaryotic community composition on carbon export would change the ratio between new and regenerated nutrient supply and, in turn, affect the phytoplankton community structure (Mann \& Lazier 2006). The feedbacks between heterotrophic prokaryotes and phytoplankton, and those between remineralization and production processes should be considered as a very important next step for developing regional ecosystem models. Unifying them into general circulation models is also important for understanding nonequilibrium dynamics in the global carbon cycle.

Our prediction that the prokaryote metacommunity can suppress the sinking flux of POC to a level substantially lower than that that would be expected from increasing primary production is consistent with the results obtained in recent iron fertilization experiments (Boyd et al. 2000), supporting the hypothesis that enhanced remineralization of POC by prokaryotes is responsible for this pattern (Boyd et al. 2000, 2004). Future studies should focus on shifts in prokaryotic community compositions along with changes in carbon fluxes in response to iron-induced phytoplankton blooms (West et al. 2008). Other processes, such as reduced sinking of phytoplankton cells and enhanced zooplankton grazing, could also be responsible for suppression of the increase in sinking flux of POC (Boyd et al. 2007), although we assumed a fixed loss rate of particles by sinking and grazing in the present study. This implies that adaptive shifts in communitylevel traits of phytoplankton or zooplankton occur in response to iron-fertilization. It is potentially productive for future studies to include metacommunity dynamics of phytoplankton and zooplankton.

Our simulations suggest that both rapid growth of rare groups within a community and immigration of various groups into a community facilitate adaptive shifts of local prokaryotic communities in response to environmental changes (Figs. 5 \& 6). In our simulations, after bloom, the particle-attached and free-living production is about 0.30 and $1.9 \mu \mathrm{g} \mathrm{C}^{-1} \mathrm{~d}^{-1}$, respectively (the averages for $I_{\mathrm{m}}=10^{5}$ cells $\mathrm{l}^{-1} \mathrm{~d}^{-1}$ ). They are equivalent to the production of $1.5 \times 10^{7}$ cells $\mathrm{l}^{-1} \mathrm{~d}^{-1}$ of particle-attached cells and $9.5 \times 10^{7}$ cells $\mathrm{l}^{-1} \mathrm{~d}^{-1}$ of freeliving cells (we assumed $20 \mathrm{fg} \mathrm{C} \mathrm{cell}^{-1}$ : Appendix 2), respectively. Note that adaptive shifts occur with intermediate levels of immigration, $10^{5}$ to $10^{6}$ cells $\mathrm{l}^{-1} \mathrm{~d}^{-1}$, which are equivalent to only $0.1 \sim 1.0 \%$ of newly produced free-living cells. This range of the value would not be too high, although we know little about the transport of prokaryotes in oceanic environments. The above calculations suggest that shifts in composition are basically driven by the growth (autochthonous production) of rare groups within a local community, which supports a view of 'everything is everywhere'. But the results also suggest that the immigration of var- 
ious types of prokaryotes is crucial for adaptive responses to environmental changes, which supports a view of 'everything goes everywhere' (metacommunity). Adaptive responses are facilitated by immigration processes after environmental changes, which sow the seeds of adaptive ecotypes exactly when they can grow fast and/or by immigration processes before environmental changes, which help to maintain a seed bank of adaptive ecotypes when they cannot grow sufficiently (Fig. 6). In addition, our model predicts that the contribution of the immigration of cells to the adaptive responses of local communities is higher when the shorter term responses are focused on (Fig. 5a) and when the potential growth rate of rare groups are lower (Fig. 5b). However, the results are not conclusive about the relative importance of immigrated species and the indigenous rare species (a seed bank) in natural conditions. In order to test the general applicability of the metacommunity model that we developed in the present paper, future studies should examine prokaryote fluxes at a species (or ecotype) level.

Although the link between biodiversity and ecosystem functioning has been a subject of considerable debate over the past decade (Loreau et al. 2001), the theory concerning the link between broad-scale diversity and biogeochemical cycling is still immature. This is partly because biogeochemical cycling has been explained and predicted by the black box approach or compartment models without considering biodiversity and spatial heterogeneity. Our results clearly demonstrate that predictions based on the metacommunity model with flexible community traits deviate substantially from those obtained by adopting a conventional black box model approach with 'monoculture' communities. Importantly, complex adaptive systems do not always respond linearly to environmental changes, but do behave nonlinearly as we found in this study, being consistent with recent observations that indicate the prevalence of regime shifts in a range of biological communities including ocean, freshwater, and terrestrial systems (Scheffer et al. 2001, Scheffer \& Carpenter 2003). The integrative strategy proposed in the present paper can be readily applied to other systems (e.g. freshwater lakes), providing a framework for a novel research path to uncover the role of prokaryotic diversity in the regulation of the biogeochemistry of the earth, and for a better prediction of ecosystem responses to environmental changes.

Acknowledgements. We thank F. Rassoulzadegan, K. Hamasaki, and M. Kondoh for advice. This work was supported by a grant for biodiversity research of the 21st century COE (A14) and the Japan Society for the Promotion of Science (JSPS) research fellowships for young scientists to T.M., and a KAKENHI $(17201004,20310010)$ to T.N.

\section{LITERATURE CITED}

Acinas SG, Klepac-Ceraj V, Hunt DE, Pharino C, Ceraj I, Distel DL, Polz MF (2004) Fine-scale phylogenetic architecture of a complex bacterial community. Nature 430:551-554

Antia AN, Koeve W, Fischer G, Blanz T and others (2001) Basin-wide particulate carbon flux in the Atlantic Ocean: regional export patterns and potential for atmospheric $\mathrm{CO}_{2}$ sequestration. Global Biogeochem Cycles 15:845-862

Bouman HA, Ulloa O, Scanlan DJ, Zwirglmaier K and others (2006) Oceanographic basis of the global surface distribution of Prochlorococcus ecotypes. Science 312:918-921

Boyd PW, Watson AJ, Law CS, Abraham ER and others (2000) A mesoscale phytoplankton bloom in the polar Southern Ocean stimulated by iron fertilization. Nature 407:695-702

$>$ Boyd PW, Law CS, Wong CS, Nojiri Y and others (2004) The decline and fate of an iron-induced subarctic phytoplankton bloom. Nature 428:549-553

Boyd PW, Jickells T, Law CS, Blain S and others (2007) Mesoscale iron enrichment experiments 1993-2005: synthesis and future directions. Science 315:612-617

- Cho BC, Azam F (1988) Major role of bacteria in biogeochemical fluxes in the oceans interior. Nature 332:441-443

Cottrell MT, Kirchman DL (2000) Natural assemblages of marine proteobacteria and members of the CytophagaFlavobacter cluster consuming low- and high-molecularweight dissolved organic matter. Appl Environ Microbiol 66:1692-1697

> Crump BC, Hopkinson CS, Sogin ML, Hobbie JE (2004) Microbial biogeography along an estuarine salinity gradient: combined influences of bacterial growth and residence time. Appl Environ Microbiol 70:1494-1505

Curtis TP, Sloan WT, Scannell JW (2002) Estimating prokaryotic diversity and its limits. Proc Natl Acad Sci USA 99:10494-10499

de Wit R, Bouvier T (2006) 'Everything is everywhere, but, the environment selects'; What did Baas Becking and Beijerinck really say? Environ Microbiol 8:755-758

del Giorgio PA, Cole JJ (2000) Bacterial energetics and growth efficiency. In: Lirchman DL (ed) Microbial ecology of the ocean. Wiley-Liss, New York, p 289-326

DeLong EF, Karl DM (2005) Genomic perspectives in microbial oceanography. Nature 437:336-342

DeLong EF, Preston CM, Mincer T, Rich V and others (2006) Community genomics among stratified microbial assemblage in the ocean's interior. Science 311:496-503

Ducklow HW, Steinberg DK, Buesseler KO (2001) Upper ocean carbon export and the biological pump. Oceanography (Wash DC) 14:50-58

Dugdale RC, Goering JJ (1967) Uptake of new and regenerated forms of nitrogen in primary productivity. Limnol Oceanogr 12:196-206

Dunne JP, Armstrong RA, Gnanadesikan A, Sarmiento JL (2005) Empirical and mechanistic models for the particle export ratio. Global Biogeochem Cycles 19:GB4026

Elifantz H, Malmstrom RR, Cottrell MT, Kirchman DL (2005) Assimilation of polysaccharides and glucose by major bacterial groups in the Delaware Estuary. Appl Environ Microbiol 71:7799-7805

Eppley RW, Peterson BJ (1979) Particulate organic matter flux and planktonic new production in the deep ocean. Nature 282:677-680

> Fenchel T, Finlay BJ (2004) The ubiquity of small species: patterns of local and global diversity. Bioscience 54: 777-784

> Field KG, Gordon D, Wright T, Rappe M, Urbac E, Vergin K, Giovannoni SJ (1997) Diversity and depth-specific distribu- 
tion of SAR11 cluster rRNA genes from marine planktonic bacteria. Appl Environ Microbiol 63:63-70

Giovannoni SJ, Stingl U (2005) Molecular diversity and ecology of microbial plankton. Nature 437:343-348

> Green J, Bohannan BJM (2006) Spatial scaling of microbial biodiversity. Trends Ecol Evol 21:501-507

> Grossart HP, Hietanen S, Ploug H (2003) Microbial dynamics on diatom aggregates in Øresund, Denmark. Mar Ecol Prog Ser 249:69-78

Hewson I, Steele JA, Capone DG, Fuhrman JA (2006) Remarkable heterogeneity in meso- and bathypelagic bacterioplankton. Limnol Oceanogr 51:1274-1283

Kirchman DL (2002) The ecology of Cytophaga-Flavobacteria in aquatic environments. FEMS Microbiol Ecol 39:91-100

Kirchman DL, Dittel AI, Malmstrom RR, Cottrell MT (2005) Biogeography of major bacterial groups in the Delaware Estuary. Limnol Oceanogr 50:1697-1706

Kitayama K (2005) Comment on 'Ecosystem properties and forest decline in contrasting long-term chronosequences'. Science 308:633b

> Lancelot C, Hannon E, Becquevort S, Veth C, De Baar HJW (2000) Modeling phytoplankton blooms and carbon export production in the Southern Ocean: dominant controls by light and iron in the Atlantic sector in austral spring 1992. Deep-Sea Res I 47:1621-1662

Laws EA, Falkowski PG, Smith WO, Ducklow H, McCarthy JJ (2000) Temperature effects on export production in the open ocean. Global Biogeochem Cycles 14:1231-1246

Leibold M, Norberg J (2004) Biodiversity in metacommunities: Plankton as complex adaptive systems? Limnol Oceanogr 49:1278-1289

> Leibold MA, Holyoak M, Mouquet N, Amarasekare P and others (2004) The metacommunity concept: a framework for multi-scale community ecology. Ecol Lett 7:601-613

> Levin SA (1998) Ecosystems and the biosphere as complex adaptive systems. Ecosystems 1:431-436

- Loreau M, Naeem S, Inchausti P, Bengtsson J and others (2001) Ecology-biodiversity and ecosystem functioning: current knowledge and future challenges. Science 294:804-808

Loreau M, Mouquet N, Gonzalez A (2003) Biodiversity as spatial insurance in heterogeneous landscapes. Proc Natl Acad Sci USA 100:12765-12770

Mann KH, Lazier JRN (2006) Dynamics of marine ecosystems: biological-physical interactions in the oceans. Blackwell, Oxford

- Martin AP (2003) Phytoplankton patchiness: the role of lateral stirring and mixing. Prog Oceanogr 57:125-174

> Miki T, Yamamura N (2005) Theoretical model of interactions between particle-associated and free-living bacteria to predict functional composition and succession in bacterial communities. Aquat Microb Ecol 39:35-46

Morris RM, Rappé MS, Connon SA, Vergin KL, Siebold WA, Carison CA, Giovannoni SJ (2002) SAR11 clade dominates ocean surface bacterioplankton communities. Nature 420: 806-810

Murray AE, Preston CM, Massana R, Taylor LT, Blakis A, Wu K, DeLong EF (1998) Seasonal and spatial variability of bacterial-archaeal assemblages in the coastal waters near Anvers Island, Antarctica. Appl Environ Microbiol 64: 2585-2595

Nagata T, Fukuda H, Fukuda R, Koike I (2000) Bacterioplankton distribution and production in deep Pacific waters: large-scale geographic variations and possible coupling with sinking particle fluxes. Limnol Oceanogr 45:426-435
Norberg J, Swaney DP, Dushoff J, Lin J, Casagrandi R, Levin SA (2001) Phenotypic diversity and ecosystem functioning in changing environments: a theoretical framework. Proc Natl Acad Sci USA 98:11376-11381

Painchaud J, Lefaivre D, Therriault JC, Legendre L (1996) Bacterial dynamics in the upper St. Lawrence estuary. Limnol Oceanogr 41:1610-1618

Pernthaler J, Glöckner FO, Unterholzner S, Alfreider A, Psenner R, Amann R (1998) Seasonal community and population dynamics of pelagic bacteria and archaea in a high mountain lake. Appl Environ Microbiol 64:4299-4306

> Pommier T, Pinhassi A, Hagström Å (2005) Biogeographic analysis of ribosomal RNA clusters from marine bacterioplankton. Aquat Microb Ecol 41:79-89

Riemann L, Winding A (2001) Community dynamics of free-living and particle-associated bacterial assemblages during a freshwater phytoplankton bloom. Microb Ecol 42:274-285

Riemann L, Steward GF, Azam F (2000) Dynamics of bacterial community composition and activity during a mesocosm diatom bloom. Appl Environ Microbiol 66:578-587

Rivkin RB, Legendre L (2001) Biogenic carbon cycling in the upper ocean: effects of microbial respiration. Science 291: $2398-2400$

Robarts RD, Zohary T, Waiser MJ, Yacobi YZ (1996) Bacterial abundance, biomass, and production in relation to phytoplankton biomass in the Levantine Basin of the southeastern Mediterranean Sea. Mar Ecol Prog Ser 137:273-281

Sarmiento JL, Gruber N (2006) Ocean biogeochemical dynamics. Princeton University, Princeton, NJ

Sarmiento JL, Hughes TMC, Stouer RJ, Manabe S (1998) Simulated response of the ocean carbon cycle to anthropogenic climate warming. Nature 393:245-249

Scheffer M, Carpenter S (2003) Catastrophic regime shifts in ecosystems: linking theory to observation. Trends Ecol Evol 18:648-656

> Scheffer M, Carpenter S, Foley JA, Folke C, Walker B (2001) Catastrophic shifts in ecosystems. Nature 413:591-596

Smith DC, Simon M, Alldredge AL, Azam F (1992) Intense hydrolytic enzyme-activity on marine aggregates and implications for rapid particle dissolution. Nature 359:139-142

- Spall SA, Richards KJ (2000) A numerical model of mesoscale frontal instabilities and plankton dynamics. I. Model formulation and initial experiments. Deep-Sea Res I 47:1261-1301

Strom SL (2000) Bacterivory: interactions between bacteria and their grazers. In: Kirchman DL (ed) Microbial ecology of the oceans. Wiley-Liss, New York, p 351-386

> Thingstad TF, Lignell R (1997) Theoretical models for the control of bacterial growth rate, abundance, diversity and carbon demand. Aquat Microb Ecol 13:19-27

> Venter JC, Remington K, Heidelberg JF, Halpern AL and others (2004) Environmental genome shotgun sequencing of the Sargasso Sea. Science 304:66-74

West NJ, Obernosterer I, Zemb O, Lebaron P (2008) Major differences of bacterial diversity and activity inside and outside of a natural iron-fertilized phytoplankton bloom in the Southern Ocean. Environ Microbiol 10:738-756

Williams PJleB (2000) Heterotrophic bacteria and the dynamics of dissolved organic material. In: Kirchman DL (ed) Microbial ecology of the oceans. Wiley-Liss, New York, p 153-200

Zubkov MV, Fuchs BM, Tarran GA, Burkill PH, Amann R (2002) Mesoscale distribution of dominant bacterioplankton groups in the northern North Sea in early summer. Aquat Microb Ecol 29:135-144 
Appendix 1. Numerical calculations

At the beginning of $t$-th time step, the abundance of freeliving cells and of particle-attached cells (i.e. aggregates) of Ecotype $j$ are set as $\boldsymbol{F}[j, t]\left(10^{9}\right.$ cells $\left.\mathbf{l}^{-1}\right)$ and $\boldsymbol{A}[\boldsymbol{j}, t]\left(10^{9}\right.$ particles $1^{-1}$ ), respectively. The concentrations of fresh POC and DOC are set as POC $t]\left(\mu \mathrm{C} \mathrm{l}^{-1}\right)$ and DOC $\left.t\right]$ ( $\left.\mu \mathrm{g} \mathrm{C}^{-1}\right)$, respectively. After loss events due to mortality (densityindependent; ecotype-specific, density-dependent; nonspecific density-dependent mortality; see Appendices 2 \& 3) and sinking, among the surviving fraction of free-living cells of Ecotype $j$, the cells in fraction $a_{j}$ change their physiological state and become participants in competition for colonizing new particles (denoted as FtoA $[j]$ ), while those in the other fraction remain in the free-living state and become participants in competition for consumption of DOC (denoted as FtoF $[j])$. Among the surviving fraction of aggregates of Ecotype $j$, the fraction $h_{\mathrm{j}}$ is hydrolyzed to smaller molecules with efficiency $e_{\mathrm{H}}$, whereas the other fraction $1-h_{\mathbf{j}}$ remains as aggregates $\left(\mathbf{A}_{\mathbf{S T A Y}}[j]\right)$. Note that the fraction $1-e_{\mathrm{H}}$ of hydrolyzed carbon is respired as $\mathrm{CO}_{2}$. Fraction $u_{j}$ of the hydrolyzed carbon is used for production of new cells (denoted as ProdA[j]) with efficiency $e_{\mathrm{P}}$, where $e_{\mathrm{P}}$ is prokaryotic growth efficiency. Note that fraction $1-e_{\mathrm{p}}$ of carbon consumption is respired as $\mathrm{CO}_{2}$. The unassimilated fraction $\left(1-u_{\mathrm{j}}\right)$ of hydrolyzed carbon is released as DOC (denoted as $\operatorname{ReDOC}[j]$ ). Among ProdA[ $j]$ plus cells originally attached on hydrolyzed POC, cells in fraction $d_{\mathrm{j}}$ change their physiological state to become free-living and become participants in competition for DOC (denoted as AtoF $[j]$ ), while those in the other fraction become participants in competition for POC (denoted as AtoA[ $j]$ ). Appendix 2 summarizes the parameters, and the above variables are calculated in Appendix 3.

Using these variables, we can calculate the changes in prokaryotic abundance and concentrations of POC and DOC.

The concentration of fresh particles available for prokaryotes is calculated as follows (denoted as $\mathbf{P O C} \mathbf{C}_{\text {NEW }}$ ):

$\mathbf{P O C}_{\text {NEW }}=$ particles surviving from sinking and grazing + new production $=\mathrm{POC}[t]\left(1-m_{\mathrm{V}}-m_{\mathrm{G}}\right)+s_{\mathrm{POC}}$

The concentration of DOC is calculated as follows (denoted as $\mathbf{D O C}_{\mathrm{NEW}}$ ):

DOC $_{\text {NEW }}=$ present concentration + new production + release from aggregates $=\mathrm{DOC}[t]+S_{\mathrm{DOC}}+\sum_{j=1}^{j=N} \operatorname{ReDOC}[j]$

Then, the abundance of particles colonized by the cells of Ecotype $j\left(\mathbf{A}_{\mathrm{NEw}}[j]\right)$ can be calculated as follows, if the Poisson process for the colonization is assumed and only 1 colonizing cell is assumed to survive on 1 particle:

$\mathbf{A}_{\text {NEW }}[j]=$ abundance of fresh particles $\times$ probability that 1 particle is colonized by no less than 1 prokaryotic cell of any ecotype $\times$ probability that the surviving cell belongs to Ecotype $j=$

$$
\begin{array}{r}
\left(\mathrm{POC}_{\mathrm{NEW}} / p_{\mathrm{POC}}\right)\left\{1-\exp \left(-k_{\mathrm{A}} \sum_{i=1}^{i=N}(\mathrm{FtoA}[i]+\operatorname{AtoA}[i])\right)\right\} \\
\times \frac{\text { FtoA }[j]+\operatorname{AtoA}[j]}{\sum_{i=1}^{i=N}(\operatorname{FtoA}[i]+\operatorname{AtoA}[i])}
\end{array}
$$

where $p_{\mathrm{POC}}$ is carbon content per particle.

This holds only if $\left(\mathrm{POC}_{\mathrm{NEW}} / p_{\mathrm{POC}}\right)\left\{1-\exp \left(-k_{\mathrm{A}} \sum_{i=1}^{i=N}(\mathrm{FtoA}[i]\right.\right.$

$+\operatorname{AtoA}[i]))\}<\sum_{i=1}^{i=N}($ FtoA $[i]+$ AtoA $[i])$, because each cell can colonize only 1 particle, and, in this case, the concentration of fresh POC is changed to:
$\mathbf{P O C}_{\mathrm{AFTER}}=\mathrm{POC}_{\mathrm{NEW}} \exp \left(-k_{\mathrm{A}} \sum_{i=1}^{i=N}(\mathrm{FtoA}[i]+\mathrm{AtoA}[i])\right)$

Therefore, if $\left(\mathrm{POC}_{\mathrm{NEW}} / p_{\mathrm{POC}}\right)\left\{1-\exp \left(-k_{\mathrm{A}} \sum_{i=1}^{i=N}\right.\right.$ (FtoA $[i]+$ $+\operatorname{AtoA}[i]))\}>\sum_{i=1}^{i=N}($ FtoA $[i]+\operatorname{AtoA}[i])$,

$\mathbf{A}_{\mathrm{NEW}}[j]=\mathbf{F t o} \mathbf{A}[j]+\operatorname{Ato} \mathbf{A}[j]$.

In this case, the concentration of POC is changed to:

$\mathbf{P O C}_{\mathrm{AFTER}}=\mathrm{POC}_{\mathrm{NEW}}-p_{\mathrm{POC}} \sum_{i=1}^{i=N}(\mathrm{FtoA}[i]+\mathrm{AtoA}[i])$

The abundance of DOC consumed by the cells of Ecotype $j(\mathbf{D O C u P}[j])$ is:

$\operatorname{DOCuP}[j]=$ abundance of DOC molecules $\times$ probability of encounter between DOC and cells of any ecotype $\times$ probability that encountering cell belongs to Ecotype $j$ :

$\operatorname{DOCuP}[j]=$

$$
\begin{array}{r}
\operatorname{DOC}_{\mathrm{NEW}}\left\{1-\exp \left(-k_{\mathrm{F}} \sum_{i=1}^{i=N}(\operatorname{AtoF}[i]+\mathrm{FtoF}[i])\right)\right\} \\
\times \frac{\operatorname{AtoF}[j]+\mathrm{FtoF}[j]}{\sum_{i=1}^{i=N}(\operatorname{AtoF}[i]+\mathrm{FtoF}[i])}
\end{array}
$$

If we consider the trade-off between the efficiency of using POC and that of using DOC, the above equation is modified as follows:

$$
\begin{aligned}
& \operatorname{DOCuP}[j]= \\
& \operatorname{DOC}_{\mathrm{NEW}}\left\{1-\exp \left(-k_{\mathrm{F}} \sum_{i=1}^{i=N}\left(1-h_{i}\right)(\operatorname{AtoF}[i]+\mathrm{FtoF}[i])\right)\right\} \\
& \times \frac{\left(1-h_{j}\right)(\operatorname{AtoF}[j]+\text { FtoF }[j])}{\sum_{i=1}^{i=N}\left(1-h_{i}\right)(\operatorname{AtoF}[i]+\operatorname{FtoF}[i])}
\end{aligned}
$$

This is the assumption that the ecotype with higher efficiency of using POC (i.e. the ecotype with higher hydrolysis rate $\left[h_{j}\right]$ ) has lower consumption rate of DOC; the 'effective' number of free-living cells is calculated as the number of free-living cells weighted by $\left(1-h_{\mathrm{j}}\right)$.

For both assumptions, the number of newly produced free-living cells of Ecotype $j(\operatorname{ProdF}[j])$ is:

$$
\operatorname{ProdF}[j]=p_{p}{ }^{-1} e_{\mathrm{p}} \operatorname{DOCuP}[j],
$$

where $e_{\mathrm{P}}$ is the growth efficiency of prokaryotes, noting that the fraction $1-e_{\mathrm{P}}$ of carbon consumption is respired as $\mathrm{CO}_{2}$.

In this production process, the DOC concentration is changed to DOC $_{\text {AFTER, }}$ which can be calculated as:

$$
\mathbf{D O C}_{\mathrm{AFTER}}=\mathrm{DOC}_{\mathrm{NEW}} \exp \left(-k_{\mathrm{F}} \sum_{j=1}^{j=N}(\mathrm{AtoF}[j]+\mathrm{FtoF}[j])\right)
$$

Then, the abundance of free-living cells of Ecotype $j$ is changed to $\mathbf{F}_{\mathrm{AFTER}}[j]$ as follows:

$\mathrm{F}_{\mathrm{AFTER}}[j]=$ abundance of remaining free-living cells + abundance of cells coming from particles + abundance of newly produced free-living cells + abundance of cells that could not colonize fresh particles $=\mathbf{F t o F}[j]+\operatorname{AtoF}[j]+\operatorname{ProdF}[j]+$ (FtoA $[j]+\operatorname{Ato} \mathbf{A}[j]-\mathbf{A}_{\text {NEW }}[j]$ ).

Similarly, the abundance of aggregates colonized by Ecotype $j$ is changed to $\mathbf{A}_{\mathbf{A F T E R}}[j]$ as follows:

$\mathbf{A}_{\text {AFTER }}[j]=$ abundance of remaining aggregates + abundance of newly formed aggregates $=\mathbf{A}_{\mathbf{S T A Y}}[j]+\mathbf{A}_{\mathrm{NEW}}[j]$. 
Appendix 1 (continued)

The variables for the next time step $[(t+1)$ th $]$ are calculated as follows:

$$
\begin{aligned}
& \text { POC }[t+1]=\text { POC }_{\text {AFTER }} \\
& \text { DOC }[t+1]=\text { DOC }_{\text {AFTER }} \\
& \text { A }[j, t+1]=\mathbf{A}_{\text {AFTER }}[j]
\end{aligned}
$$

For free-living cells, we assumed deterministic processes of immigration from the metacommunity. Then, let $I_{\mathrm{m}}$ be the total abundance of immigrating cells. We assumed that the relative abundances of all ecotypes were equal in the metacommunity, and thus that the abundance of immigrants of Ecotype $j$ is $I_{\mathrm{m}} / N$, independent of $j$. On the other hand, emigrants from the local community were assumed to be proportional to the local abundance of each ecotype. Then, the abundance of emigrants is calculated as:

$$
I_{\mathrm{m}} \frac{\mathrm{F}_{\mathrm{AFTER}}[j]}{\sum_{j=1}^{j=N} \mathrm{~F}_{\mathrm{AFTER}}[j]}
$$

Therefore, after immigration and emigration of cells, the abundance of free-living cells $\left(\mathbf{F}_{\mathrm{BEFORE}}[j]\right)$ is calculated as:

$$
\mathbf{F}[j, t+1]=\mathrm{F}_{\mathrm{AFTER}}[j]\left(1-\frac{I_{\mathrm{m}}}{\sum_{j=1}^{j=N} \mathrm{~F}_{\mathrm{AFTER}}[j]}\right)+\frac{I_{\mathrm{m}}}{N}
$$

This is the case for deterministic immigration with 'balanced emigration', assuming that total number of emigra- tion cases is the same as that of immigration. We also prepared 3 alternative assumptions for immigration. The first case is that only deterministic immigration of cells are considered:

$$
\mathbf{F}[j, t+1]=\mathrm{F}_{\mathrm{AFTER}}[j]+\frac{I_{\mathrm{m}}}{N}
$$

We also considered the case with the stochastic immigration of cells:

$$
\mathrm{F}[j, t+1]=\mathrm{F}_{\mathrm{AFTER}}[j]+\frac{I_{\mathrm{m}}}{N} \varepsilon_{j}[t]
$$

where $\varepsilon_{\mathrm{j}}[t]$ is a random number from the range $(0,2)$, with the average of 1 for each ecotype.

In addition, we considered the case that the immigration rate depends on ecotype-specific traits. For example, we assumed that the ecotype with a higher detachment rate from particles has a greater dispersal ability among local communities. For this ecotype-specific immigration rate, we used the following equation:

$$
\mathbf{F}[j, t+1]=\mathrm{F}_{\mathrm{AFTER}}[j]+d_{j} \frac{I_{\mathrm{m}}}{N}
$$

\begin{tabular}{|c|c|c|c|}
\hline Symbol & Definition & Unit & Default \\
\hline$N$ & Number of ecotypes in the metacommunity & - & 1000 \\
\hline$a_{j}$ & Attachment rate to POC of Ecotype $j$ & - & $0.0-1.0$ \\
\hline$d_{\mathrm{j}}$ & Detachment rate from POC of Ecotype $j$ & - & $0.0-1.0$ \\
\hline$h_{\mathrm{j}}$ & Hydrolysis rate of POC of Ecotype $j$ & - & $0.0-1.0$ \\
\hline$u_{\mathrm{j}}$ & Uptake ratio of hydrolyzed POC of Ecotype $j$ & - & $0.0-u_{\mathrm{MAX}}$ \\
\hline$u_{\mathrm{MAX}}$ & Maximum uptake ratio of hydrolyzed POC & - & $0.5^{\mathrm{a}}$ \\
\hline$m_{\mathrm{G}}$ & Mortality rate of prokaryotes and POC due to grazing & $\mathrm{d}^{-1}$ & $0.1^{\mathrm{b}, \mathrm{c}}$ \\
\hline$m_{\mathrm{DS}}$ & Coefficient for ecotype-specific, density-dependent mortality rate of prokaryotes & $\mathrm{d}^{-1}\left(10^{9} \text { cells }\right)^{-1}$ & 0.0 \\
\hline$m_{\mathrm{DN}}$ & Coefficient for non-specific, density-dependent mortality rate of prokaryotes & $\mathrm{d}^{-1}\left(10^{9} \text { cells }\right)^{-1}$ & 0.0 \\
\hline$m_{\mathrm{V}}$ & Sinking rate of $\mathrm{POC}$ and aggregates & $\mathrm{d}^{-1}$ & 0.1 \\
\hline$e_{\mathrm{H}}$ & Efficiency of hydrolysis of POC to DOC & - & 0.99 \\
\hline$e_{\mathrm{P}}$ & Growth efficiency of prokaryotes & - & $0.15^{\mathrm{d}}$ \\
\hline$p_{\mathrm{P}}$ & Carbon content per prokaryotic cell & $\mu \mathrm{g} \mathrm{C}\left(10^{9} \text { cells }\right)^{-1}$ & $20^{\mathrm{e}}$ \\
\hline$p_{\mathrm{POC}}$ & Carbon content per POC & $\mu \mathrm{g}$ C particle p $^{-1}$ & $100 p_{\mathrm{P}}$ \\
\hline$k_{\mathrm{A}}$ & Encounter efficiency between POC and cells & $\left(10^{9} \text { cells } 1^{-1}\right)^{-1}$ & 2.0 \\
\hline$k_{\mathrm{F}}$ & Encounter efficiency between DOC and cells & $\left(10^{9} \text { cells } \mathrm{l}^{-1}\right)^{-1}$ & 1.0 \\
\hline$s_{\mathrm{DOC}}$ & Supply rate of DOC & $\mu g \mathrm{C}^{-1} \mathrm{~d}^{-1}$ & $10.0^{\mathrm{e}}$ \\
\hline$S_{\mathrm{POC}}$ & Supply rate of POC & $\mu \mathrm{g} \mathrm{C}^{-1} \mathrm{~d}^{-1}$ & $1.0-10.0^{\mathrm{e}}$ \\
\hline$I_{\mathrm{m}}$ & Immigration rate from the metacommunity & $10^{9}$ cells $\mathrm{l}^{-1} \mathrm{~d}^{-1}$ & $1.0^{-9}-1.0^{-1}$ \\
\hline$T_{\text {bloom }}$ & Period of bloom & $\mathrm{d}$ & 100 \\
\hline $\begin{array}{l}{ }^{\mathrm{a}} \text { Maxim } \\
{ }^{\mathrm{b}} \text { Strom } \\
{ }^{\mathrm{c}} \text { Grossar } \\
{ }^{\mathrm{d}} \text { del Gio } \\
{ }^{\text {e William }}\end{array}$ & $\begin{array}{l}\text { m uptake ratio from POC is assumed to be } \ll 1.0 \text {, based on Smith et al. (1992) } \\
\text { 000) } \\
\text { et al. (2003) } \\
\text { gio \& Cole }(2000) \\
(2000)\end{array}$ & & \\
\hline
\end{tabular}

At $t=0$, the initial density of each ecotype is determined as $\mathbf{F}[j, 0]=0.01 / N$ and as $\mathbf{A}[j, 0]=0.0$ for all $j$. Even if we randomly chose initial densities for each ecotype, the results were the same as the deterministic case (results are not shown). The initial concentration of POC and DOC (POC[0] and $\mathbf{D O C}[0]$ ) is 1.0 and 1.0, respectively.

Appendix 2. Parameter values used to run numerical simulations 
Appendix 3. Variables for numerical simulations

FtoF $[j]=$ Free-living cells that do not change their state

$$
=\left(1-a_{\mathrm{j}}\right)\left(1-m_{\mathrm{G}}-m_{\mathrm{DS}} F[j, t]-m_{\mathrm{DN}} \sum_{i=1}^{i=N} F[i, t]\right) \mathrm{F}[j, t]
$$

FtoA $[j]=$ Free-living cells that change their state to colonize POC

$$
=a_{\mathrm{j}}\left(1-m_{\mathrm{G}}-m_{\mathrm{DS}} F[j, t]-m_{\mathrm{DN}} \sum_{i=1}^{i=N} F[i, t]\right) \mathrm{F}[j, t]
$$

$\operatorname{Prod} \mathbf{A}[j]=$ Newly produced cells from aggregates

$$
=p_{\mathrm{P}}{ }^{-1} e_{\mathrm{P}} u_{\mathrm{j}} e_{\mathrm{H}} h_{\mathrm{j}}\left(1-m_{\mathrm{V}}-m_{\mathrm{G}}-m_{\mathrm{DS}} A[j, t]-m_{\mathrm{DN}} \sum_{i=1}^{i=N} A[i, t]\right) \mathrm{A}[j, t]
$$

$\operatorname{ReDOC}[j]=$ DOC release from hydrolyzed POC

$$
=\left(1-u_{\mathrm{j}}\right) p_{\mathrm{POC}} e_{\mathrm{H}} h_{\mathrm{j}}\left(1-m_{\mathrm{V}}-m_{\mathrm{G}}-m_{\mathrm{DS}} A[j, t]-m_{\mathrm{DN}} \sum_{i=1}^{i=N} A[i, t]\right) A[j, t]
$$

$$
\begin{aligned}
& \mathbf{A}_{\mathrm{STAY}}[j]=\text { Aggregate not hydrolyzed } \\
& \quad=\left(1-h_{\mathrm{j}}\right)\left(1-m_{\mathrm{V}}-m_{\mathrm{G}}-m_{\mathrm{DS}} A[j, t]-m_{\mathrm{DN}} \sum_{i=1}^{i=N} A[i, t]\right) \mathrm{A}[j, t]
\end{aligned}
$$

AtoF $[j]=$ Particle-attached cells that change their state to consume DOC

$$
\begin{aligned}
= & d_{\mathrm{j}}\left(p_{\mathrm{POC}} p_{\mathrm{P}}^{-1} e_{\mathrm{P}} u_{\mathrm{j}} e_{\mathrm{H}}+1\right) \\
& \times h_{\mathrm{j}}\left(1-m_{\mathrm{V}}-m_{\mathrm{G}}-m_{\mathrm{DS}} A[j, t]-m_{\mathrm{DN}} \sum_{i=1}^{i=N} A[i, t]\right) \mathrm{A}[j, t]
\end{aligned}
$$

$\operatorname{Ato} \mathbf{A}[j]=$ Particle-attached cells that do not change their state

$$
\begin{aligned}
= & \left(1-d_{\mathrm{j}}\right)\left(p_{\mathrm{POC}} p_{\mathrm{P}}^{-1} e_{\mathrm{P}} u_{\mathrm{j}} e_{\mathrm{H}}+1\right) \\
& \times h_{\mathrm{j}}\left(1-m_{\mathrm{V}}-m_{\mathrm{G}}-m_{\mathrm{DS}} A[j, t]-m_{\mathrm{DN}} \sum_{i=1}^{i=N} A[i, t]\right) \mathrm{A}[j, t]
\end{aligned}
$$

Appendix 4. General predictions do not depend on assumptions

Extensive numerical simulations revealed that the reduced efficiency of sinking flux of carbon due to adaptive shifts in the prokaryotic community is a robust prediction, which does not depend on assumptions (Fig. A1). The results from these simulations give some implications for specific effects of: (1) mortality, (2) immigration, and (3) the tradeoff. First, both the ecotype-specific, density-dependent mortality and the non-selective, density-dependent mortality suppress the adaptive shifts at intermediate levels of immigration (Fig. A1a vs. A1d,e,f,g). In addition, ecotype-specific, density-dependent mortality contributes to the adaptive shifts at very low levels of immigration (Fig. A1a vs. A1d,e,f). In other words, the degrees of increases in sinking flux of POC are $<1000 \%$, even at very low levels of immigration. This is because higher diversity is maintained under ecotype-specific, densitydependent mortality than under density-independent or non-selective, density-dependent mortality (data are not shown). Then, the populations of ecotypes, which are less competitive before the bloom but more competitive after the bloom, are maintained before the bloom at sufficient levels for rapid increases after the bloom. Second, details in immigration processes do not affect the responses of the system (Fig. A1a vs. A1b; Fig. A1d vs. A1e,f). Therefore, even if we do not know the details of immigration processes, we can argue that the average levels of immigration are the determinant of adaptive responses of the system. Third, the existence of the trade-off between the efficiency of utilizing POC and DOC suppresses the adaptive responses of the system (Fig. A1b vs. A1c; Fig. A1f vs. A1h). It is intuitively reasonable that the trade-off weakens the dominance of ecotypes with higher preference to POC after the bloom.

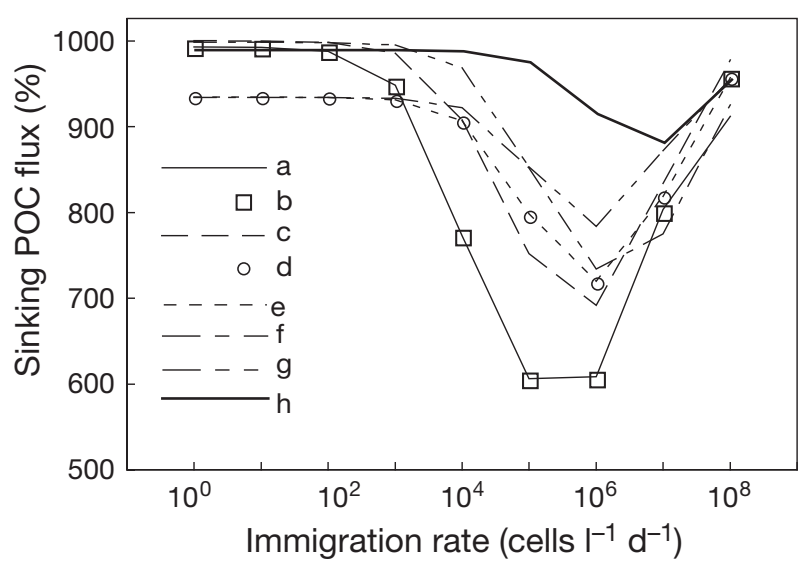

Fig. A1. Dependence of the change in sinking flux of POC on alternative assumptions. (a) Default assumptions (i.e. densityindependent mortality $\left[m_{\mathrm{G}}=0.1, m_{\mathrm{DS}}=m_{\mathrm{DN}}=0.0\right]$, deterministic immigration with balanced emigration [using Eq. A3 in Appendix 1], and no trade-off [Eq. A1]). (b) Density-independent mortality, deterministic immigration without emigration (Eq. A4), and no trade-off (Eq. A1). (c) Density-independent mortality, deterministic immigration (Eq. A4), and a trade-off (Eq. A2). (d) Ecotype-specific, density-dependent mortality $\left(m_{\mathrm{G}}=0.1, m_{\mathrm{DS}}=1.0, m_{\mathrm{DN}}=0.0\right)$, deterministic immigration (Eq. A4), and no trade-off (Eq. A1). (e) Ecotype-specific, density-dependent mortality, stochastic immigration (Eq. A5), and no trade-off (Eq. A1). (f) Ecotype-specific, density-dependent mortality, ecotype-specific immigration (Eq. A6), and no tradeoff (Eq. A1). (g) Non-specific, density-dependent mortality $\left(m_{\mathrm{G}}\right.$ $\left.=m_{\mathrm{DN}}=0.1, m_{\mathrm{DS}}=0.0\right)$, deterministic immigration (Eq. A4), and no trade-off (Eq. A1). (h) Ecotype-specific, densitydependent mortality, ecotype-specific immigration (Eq. A6), and the trade-off (Eq. A2). 